\title{
Pursuing necessary reductions in embedded GHG emissions of developed nations: will efficiency improvements and changes in consumption get us there?
}

Bjørn, Anders; Kalbar, Pradip; Elsborg Nygaard, Simon; Kabins, Simon; Jensen, Charlotte Louise; Birkved, Morten; Schmidt, Jannick; Hauschild, Michael Zwicky

\section{Published in:}

Global Environmental Change

Link to article, DOI:

10.1016/j.gloenvcha.2018.08.001

Publication date:

2018

Document Version

Peer reviewed version

Link back to DTU Orbit

Citation (APA):

Bjørn, A., Kalbar, P., Elsborg Nygaard, S., Kabins, S., Jensen, C. L., Birkved, M., Schmidt, J., \& Hauschild, M. Z. (2018). Pursuing necessary reductions in embedded GHG emissions of developed nations: will efficiency improvements and changes in consumption get us there? Global Environmental Change, 52, 314-324. https://doi.org/10.1016/j.gloenvcha.2018.08.001

\section{General rights}

Copyright and moral rights for the publications made accessible in the public portal are retained by the authors and/or other copyright owners and it is a condition of accessing publications that users recognise and abide by the legal requirements associated with these rights.

- Users may download and print one copy of any publication from the public portal for the purpose of private study or research.

- You may not further distribute the material or use it for any profit-making activity or commercial gain

- You may freely distribute the URL identifying the publication in the public portal 


\title{
Pursuing necessary reductions in embedded GHG emissions of developed nations: will efficiency improvements and changes in consumption get us there?
}

$\underline{\text { Anders Biørn }}{ }^{1,5^{*}}$, Pradip Kalbar ${ }^{1,6}$, Simon Elsborg Nygaard ${ }^{2}$, Simon Kabins ${ }^{2}$, Charlotte Louise Jensen ${ }^{3}$, Morten Birkved $^{1}$, Jannick Schmidt ${ }^{4}$ and Michael Zwicky Hauschild ${ }^{1}$

${ }^{1}$ The Technical University of Denmark, Department of Management Engineering, Building 424, 2800 Kgs. Lyngby, Denmark.

${ }^{2}$ Aarhus University, Department of Psychology and Behavioural Sciences, Building 1350, 8000 Aarhus C, Denmark.

${ }^{3}$ Aalborg University, Department of Planning, A.C. Meyers Vænge 15, 2450 Copenhagen SV, Denmark.

${ }^{4}$ Aalborg University, Department of Planning, Rendsburggade 14, 9000 Aalborg, Denmark.

${ }^{5}$ CIRAIG, Polytechnique Montréal, 3333 Queen-Mary Road, H3V 1A2, Montréal, QC, Canada.

${ }^{6}$ Centre for Urban Science and Engineering (CUSE), Indian Institute of Technology Bombay, Powai, Mumbai 400 076, India.

*E-mail contact: anders.bjoern@polymtl.ca

\begin{abstract}
The COP21 summit in Paris led to a policy commitment of limiting the global temperature increase to 1.5$2.0^{\circ} \mathrm{C}$ and this can be translated to a global annual greenhouse gas (GHG) emission budget that is shrinking rapidly throughout the $21^{\text {st }}$ century. Here, we estimate the reductions in GHG emission intensities of technologies that will be required for the embedded GHG emissions of a developed nation to stay within its fair share of a global emission budget in the year 2050. The estimates are made for different conceivable developments in consumption patterns in the case of Denmark, based on a large survey of current consumption patterns. To evaluate whether the required emission intensity reductions are likely to be met, they are compared to historic time series of emission intensities and to projections for 2050, based on policies currently in place, for ten technologies that have a high contribution to current GHG emissions.
\end{abstract}

We estimate that emission intensities must be reduced by factors of 2-12 and 5-14, depending on the development in consumption, for the 2.0 and $1.5{ }^{\circ} \mathrm{C}$ climate goals, respectively. Of the ten selected technologies, only electricity supply is projected to, partially, meet the most strict reduction target, applying to a scenario where all inhabitants in 2050 consume as the most consuming inhabitants today. The results indicate that both a change in "consumption as usual" and in "business as usual" is needed for developed nations to meet equitable climate targets. This has implications for national and international policies targeting GHG emission intensities and may require a new orientation of policies to consider the societal structures around consumption.

\section{Introduction}

Research in sustainability science typically takes either a technology- or a consumer perspective. Technology-oriented research addresses the question of how to reduce the environmental pressures associated with producing predetermined quantities of goods and services and uses concepts and tools 
Bjørn, A., Kalbar, P., Elsborg Nygaard, S., Kabins, S., Jensen, C. L., Birkved, M., Schmidt, J., Hauschild, M. Z. (2018). Pursuing necessary reductions in embedded GHG emissions of developed nations: will efficiency improvements and changes in consumption get us there? Global Environmental Change 52, 314-324. DOI : 10.1016/j.gloenvcha.2018.08.001

such as life cycle assessment (ISO, 2006a, 2006b), eco-design (McAloone and Bey, 2009) and environmentally extended input output (EEIO) analysis (Wiedmann, 2009). Technology-oriented research either considers environmental pressures within defined territories or pressures "embedded" in goods and services and occurring in multiple territories throughout their supply chains (sometimes called consumption-based accounting (Kokoni and Skea, 2014)). By comparison, consumer-oriented research uses a variety of scientific disciplines, such as economy, psychology and sociology, to address the question of how individuals and groups of people can consume in less environmentally harmful ways (Creutzig et al., 2018). Policy interventions targeting technology and consumers can be seen as two levers for attempting to ensure the conditions for sustainable development by preventing the transgression of environmental carrying capacities (Rees, 1996; Sayre, 2008) or planetary boundaries (Rockström et al., 2009; Steffen et al., 2015). Lately, there has been a strong focus in sustainability science on the policy commitment of the Paris Agreement to limiting global temperature increase to 1.5-2.0 degrees Celsius. Climate change science and integrated assessment modelling has led to a translation of this temperature goal to proposals of a global annual GHG emission budget that is shrinking rapidly throughout the $21^{\text {st }}$ century (van Vuuren et al., 2011).

Absolute emission budgets, and carrying capacities in general, poses a challenge for the common division of sustainability science into technology- and consumer oriented research: Solely taking a technology perspective in estimating how much the efficiencies of technologies must increase (see, for example, Girod et al. (2013) and PwC (2015)), means neglecting the potential effect of a pathway that diverges from "consumption as usual". Likewise, solely taking a consumer perspective in exploring how, physically and practically, a person or a household can live within what may be considered its "fair share" of carrying capacity (see, for example, GFN (2016) and Laakso and Lettenmeier (2014)), means disregarding the effect of efficiency improvements of technologies on the solution space. In other words, while the potentials of using either the technology- or the consumer related policy intervention lever for developing within carrying capacities have been separately studied, their combined potential is still not well-understood.

This study examines the quantitative potentials of both levers in the pursuit of absolute targets for embedded GHG emissions of a nation. Our overarching research question is: "Can foreseeable efficiency improvements of technologies and conceivable changes in consumption patterns allow a developed nation to make its fair contribution to meeting the global temperature goals of the Paris Agreement?" We explore foreseeable efficiency improvements of technologies through scenarios that are based on current policies (i.e. using a frozen policy assumption). Different conceivable changes in consumption patterns within a nation are developed from observed variations between current carbon footprints of individuals, estimated from survey data. While policy targets for GHG emissions are often of a territorial nature, e.g. in the context of the Kyoto Protocol and the Paris Agreement, emissions embedded in goods and services are of focus in this study. This means taking the perspective that a nation is responsible for GHG emissions occurring outside its territory as a result of its consumption. For convenience, we generally use the term "carbon footprint" for embedded GHG emissions throughout this study.

Denmark was chosen as a case due to the large availability of environmentally relevant data on Danish consumption and technology. Based on the overarching research question presented above, the following three technical research questions were developed:

1. What is the distribution of personal carbon footprints across the Danish population and what is the contribution of different goods and services to the footprints? 
Bjørn, A., Kalbar, P., Elsborg Nygaard, S., Kabins, S., Jensen, C. L., Birkved, M., Schmidt, J., Hauschild, M. Z. (2018). consumption get us there? Global Environmental Change 52, 314-324. DOI : 10.1016/j.gloenvcha.2018.08.001

2. Which reductions in GHG emission intensities of technologies used to deliver goods and services consumed in Denmark will be required in the year 2050 to comply with the temperature goals of the Paris Agreement for the range of consumption patterns currently observed in Denmark?

3. Are these reduction requirements likely to be met, judging from historical development in technological efficiencies and future projections based on policies currently in place?

We focus on the year 2050 because it represents a time where drastic reductions in global emissions, compared to current levels, will be required in order to meet climate goals (Rogelj et al., 2015; Rogelj et al., 2012), but also a time that is close enough to be relevant to current policy decisions (van Vuuren et al., 2015).

The novelty of this study primarily lies in its integration of a technology- and consumer perspective. An integrative approach was previously taken by Girod et al. (2014), who discussed policies for removing barriers that prevent individuals from choosing existing goods and services that have carbon footprints low enough to, collectively, meet 2050 per capita emission target calculated by Girod et al. (2013). In their work, however, it is unclear whether an individual that only consumes the identified low-carbon goods and services (e.g. resorts to biking for all transportation) can, in practice, function in current societies, i.e. whether the required consumption pattern is obtainable. Similarly, de Koning et al. (2016) and Grubler et al. (2018) considered the potentials of low-carbon technologies as well as changes in consumption to align global GHG emissions with an emission budget for 2050, but these consumption changes were largely theoretical. By contrast, this paper studies potential consumption changes that reflect self-reported actual consumption patterns from a large survey. Another novelty of our study is the comparison of the estimated required reduction in GHG emission intensity to historical and foreseeable future trends in emission intensities of important technologies. Further, we discuss the implications of our findings for climate change policies and we use practice theory (Røpke, 2009) to outline how policies may better consider the social dimension of consumption. Although the studied technologies and consumption patterns reflect a Danish setting, the conclusions drawn are relevant for many other developed nations and the methodological approach is universally applicable.

\section{Methods}

The aforementioned three research questions are addressed one by one in the following sub-sections. Figure 1 offers an overview of the methodological steps involved in addressing the three questions, the types of data sources involved and the steps in which uncertainties are assessed quantitatively. Additional uncertainties are addressed qualitatively in Section 4.1 . 


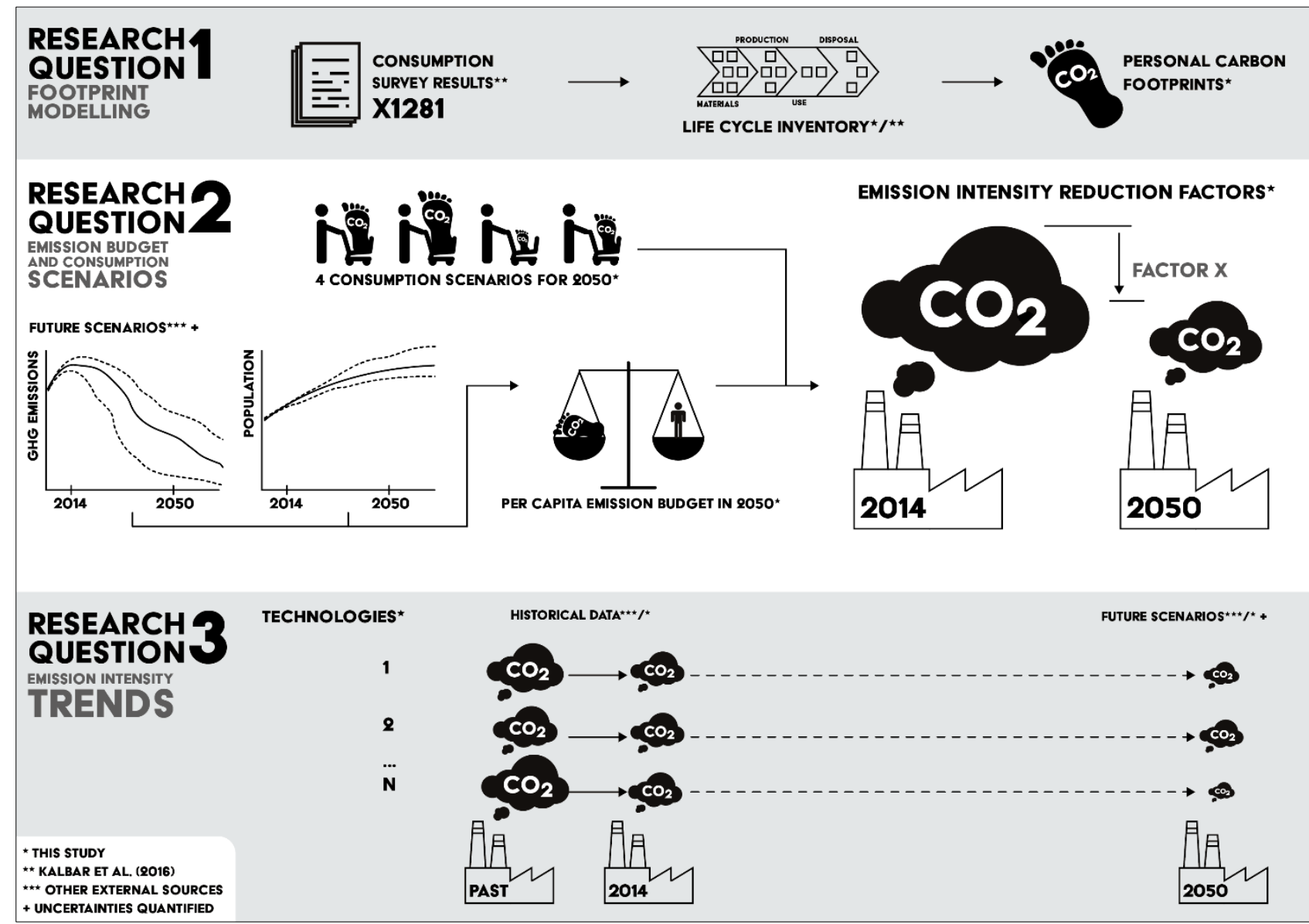

Figure 1: Overview of methodological steps.

\subsection{Personal carbon footprints}

The first step of the footprint calculations was to obtain information on quantities of, or expenditure on, goods and services consumed by a wide segment of Danish inhabitants during one year. We used survey results from Kalbar et al. (2016), who gathered responses from 1281 inhabitants living in urban areas during 1 year, stretching over 2013-2014 (Kalbar et al., 2016). The consumption data covers the seven categories of food, dwelling, thermal energy, electricity, road transport, air transport and additional goods and services. We assume that the carbon footprints to be calculated are valid for the year 2014 when later comparing them to time series of GHG emission intensities (see Section 2.3).

Next, a life cycle inventory (LCI) model for the 2014 consumption of each respondent was constructed based on the survey data. As a basis, we here adopted the LCI model constructed in Kalbar et al. (2016), which is based on a combination of the Ecoinvent 2.2 and 3.1 databases (Association Ecoinvent, 2018). Goods and services not covered by Ecoinvent were modelled by Kalbar et al. (2016) using the EEIO database FORWAST (Schmidt et al., 2010). For the purchasing of large consumer goods (such as a new house), production-related emissions were equally allocated to each year of the expected life times of these goods, so as to avoid variations in emissions between respondents caused by the timing of such acquisitions. Details of the LCl models adopted in this study are presented in Kalbar et al. (2016).

Embedded GHG emissions associated with public services (schools, roads, hospitals, etc.) were not covered by the LCI models of Kalbar et al. (2016). We here estimated emissions from all public services by using the Exiobase v3.3.8 hybrid input output (IO) database (Merciai and Schmidt, 2018; Stadler et al., 2018) for the 
Bjørn, A., Kalbar, P., Elsborg Nygaard, S., Kabins, S., Jensen, C. L., Birkved, M., Schmidt, J., Hauschild, M. Z. (2018). Pursuing necessary reductions in embedded GHG emissions of developed nations: will efficiency improvements and changes in consumption get us there? Global Environmental Change 52, 314-324. DOI : 10.1016/j.gloenvcha.2018.08.001

year 2011, the latest year in the database. Exiobase is a global multi-regional EEIO model and was used in a hybrid version in this study. This means that the EEIO model is based on three different sets of supply use tables (SUT) in different units: monetary, mass (dry matter) and energy. The data and methods for constructing the SUTs in Exiobase v3 are described in detail in Merciai and Schmidt (2018). The carbon footprint from public services used by each respondent in 2014 was calculated simply by dividing the total national estimate of Exiobase for 2011 by the population of Denmark in that year, which gave a figure of 3.0 ton $\mathrm{CO}_{2}$-eq. This pragmatic approach does not capture variations between the use of public services amongst individuals of a population, but the survey responses did not allow us to make such differentiations.

Having constructed a complete $\mathrm{LCl}$ model, the carbon footprints were finally calculated by multiplying the $\mathrm{LCl}$ results (the total life cycle quantities of different GHG emissions) by emission-specific characterization factors. These factors are taken from the GWP-100 indicator (IPCC, 2013) and account for the cumulated radiative forcing of $\mathrm{GHGs}$, relative to the radiative forcing of $\mathrm{CO}_{2}$, over a time-interval of 100 years.

\subsection{Required reductions in GHG emissions intensities}

The first step in calculating the required reductions in GHG emission intensities was to construct four explorative consumption scenarios for the year 2050. These were based on the 1281 personal carbon footprint results from the consumption survey of Kalbar et al. (2016). We use the word "explorative" to stress that none of the scenarios are attempting to predict the actual future consumption of the Danish population. Instead, they should be seen as "what-if" scenarios, because they are used to calculate what the required decrease in GHG emission intensities of technologies would be, if the Danish population were to consume according to a certain consumption pattern, observed in the present population through the survey of Kalbar et al. (2016). Table 1 presents the four consumption scenarios.

Table 1: Four explorative scenarios for the consumption of the average inhabitant of Denmark in the year 2050

\begin{tabular}{|l|l|}
\hline Scenario name & Explanation \\
\hline 1:Same & Identical to the average consumption across all respondents of Kalbar et al. (2016). \\
\hline 3:Decrease & $\begin{array}{l}\text { Identical to the average consumption of the } 128 \text { respondents of Kalbar et al. (2016) that have } \\
\text { the highest carbon footprints (above the } 90^{\text {th }} \text { percentile). }\end{array}$ \\
\hline $\begin{array}{l}\text { 4:No } \\
\text { car/airplane/meat } \\
\text { the lowest carbon footprints (below the } 10^{\text {th }} \text { percentile). }\end{array}$ \\
$\begin{array}{l}\text { Identical to the average consumption of the } 47 \text { respondents of Kalbar et al. (2016) that do not } \\
\text { own a car, refrain from air travel and are vegetarian. }\end{array}$ \\
\hline
\end{tabular}

Each of the explorative scenarios represents a consumption pattern that can currently be observed within a large sample of the Danish population (Kalbar et al., 2016) and in combination they provide an indication of how much the total carbon footprint of Denmark could change if the entire population engaged with consumption patterns that groups of the population are already exhibiting. For Scenario 1:Same it is assumed that the average inhabitant in $\mathbf{2 0 5 0}$ will have the same consumption as the average respondent of Kalbar et al. (2016). The design of Scenario 2:Increase and 3:Decrease was inspired by Girod and de Haan (2009) and they can be seen as high and low extremes of current consumption patterns. Scenario 2:Increase is probably closest to "consumption as usual", considering the historical increases in private consumption within the Danish population (the per capita consumption in Denmark, measured in constant prices, increased 19\% from 1994 to 2014 (Statistics Denmark. Prices and consumption, 2016). Scenario 4:No car/airplane/meat was included to observe the effect of having zero consumption of three activities that are commonly associated with high levels of GHG emissions and for which less emission intensive alternatives are readily available. For each consumption scenario, the 2050 per capita carbon footprint, 
Bjørn, A., Kalbar, P., Elsborg Nygaard, S., Kabins, S., Jensen, C. L., Birkved, M., Schmidt, J., Hauschild, M. Z. (2018). Pursuing necessary reductions in embedded GHG emissions of developed nations: will efficiency improvements and changes in consumption get us there? Global Environmental Change 52, 314-324. DOI : 10.1016/j.gloenvcha.2018.08.001

assuming no changes in technology, was then calculated using the LCl results calculated for each survey respondent (see Section 2.1).

Next, per capita emission targets for the year 2050 were calculated based on broadly accepted scenarios of future GHG emissions and global population. The overarching aim of the Paris Agreement is to keep "the increase in the global average temperature to well below $2^{\circ} \mathrm{C}$ above pre-industrial levels and pursuing efforts to limit the temperature increase to $1.5^{\circ} \mathrm{C}^{\prime \prime}$ (UNFCCC, 2015). We therefore calculate the per capita GHG emissions of 2050 that are consistent with a temperature increase of 2.0 degrees and 1.5 degrees, respectively. For both climate goals we allocate global emissions to the per capita level based on the principle of equal global per capita allocation, meaning that each person by the year 2050 is considered entitled to the same quantity of annual GHG emissions. While this choice of allocation might seem intuitively fair, we note that others have argued for alternative allocations, e.g. considering the historic responsibilities of nations, "rights to develop" or the needs for artificial heating or cooling determined by climatic conditions (Fanning and O'Neill, 2016; Starkey, 2008).

For the 2.0 degrees goal, we followed the approach of Girod et al. (2013) and divided the median global 2050 GHG emissions of the RCP2.6 pathway (19Gt CO CO $_{2}$ eq per year, GWP-100) by the medium global population projection of the United Nations (UN) (UN, 2015) (9.725 billion), which gives 2.0 tons $\mathrm{CO}_{2}$-eq per capita. RCP2.6 is a representative pathway for a range of emission scenarios that are consistent with the ambition to maintain the global mean temperature increase below 2.0 degrees (van Vuuren et al., 2011). For quantitative assessment of the uncertainties of emission pathways, we used the $15^{\text {th }}$ and $85^{\text {th }}$ percentile of the 2050 emissions estimates of all the 101 RCP2.6 pathway scenarios of the IIASA (2014) scenario database, which were found to be 17 and $27 \mathrm{Gt} \mathrm{CO}_{2}$-eq per year, respectively. Further, taking into account the low (8.710 billion) and high (10.801 billion) variants of the UN global population projections for 2050 (UN, 2015), we obtained an uncertainty interval for the 2050 per capita target of $1.6-3.1$ tons $\mathrm{CO}_{2}$-eq.

For the 1.5 degrees goal, we divided the global median GHG emissions for 2050 for all the 1.5 degrees scenarios reviewed by Rogelj et al. (2015) (13Gt CO CO $_{2}$ eq per year, GWP-100) by the medium UN population projection, which gives 1.3 tons per capita. Rogelj et al. (2015) reported the $15^{\text {th }}$ and $85^{\text {th }}$ percentile of all the 1.5 degrees warming scenarios that they reviewed to be 6 and 16 Gtons $\mathrm{CO}_{2}$-eq per year respectively. Combined with the uncertainty of the global population projection for 2050 (see above), we obtained an uncertainty interval for the 2050 per capita target of $0.6-1.8$ tons $\mathrm{CO}_{2}$-eq. Finally, we calculated GHG emission intensity reduction factors for the four consumption scenarios by dividing the would-be 2050 carbon footprint, computed for each consumption scenario, by the calculated 2050 per capita GHG emissions targets.

It must be noted that the climate scenarios consistent with the 1.5 and 2.0 degrees climate goals assume net negative $\mathrm{CO}_{2}$ emission after the years 2050 and 2070, respectively (the $13 \mathrm{Gt} \mathrm{CO}_{2}$-eq per year 2050 carbon budget for the 1.5 degrees scenario is thus primarily made up of non- $\mathrm{CO}_{2}$ GHGs (Rogelj et al., 2015)). The net negative $\mathrm{CO}_{2}$ emissions are achieved by a massive deployment of negative emission technologies (NETs) in the scenarios, such as bioenergy combined with carbon capture and sequestration (Minx et al., 2018, 2017). Indeed, the 1.5 degree climate goal is highly challenging to meet without NETs, given that the remaining carbon budget for the entire $21^{\text {st }}$ century, by some accounts, will already be depleted around the year 2022 if current emission trends continue (Millar et al., 2017; Minx et al., 2018). 
Bjørn, A., Kalbar, P., Elsborg Nygaard, S., Kabins, S., Jensen, C. L., Birkved, M., Schmidt, J., Hauschild, M. Z. (2018). Pursuing necessary reductions in embedded GHG emissions of developed nations: will efficiency improvements and changes in consumption get us there? Global Environmental Change 52, 314-324. DOI: 10.1016/j.gloenvcha.2018.08.001

However, there is a large gap between the important role in climate change mitigation that most climate scenarios give to NETs and the slow pace of actual innovation in and deployment of NETs. Biophysical limits and social resistance are also likely to constrain a potential massive deployment (Minx et al., 2018). Unless massive deployment of NETs will actually happen, the 2050 per capita emission targets calculated above are therefore overestimated.

\subsection{Past and future GHG emission intensities of relevant technologies}

Personal carbon footprints are composed of contributions from hundreds of goods and services that each involves hundreds of industrial processes throughout their life cycles (from raw material acquisition to disposal after use). To address the third research question of the analysis (whether GHG emission reduction requirements are likely to be met, see Section 1), a manageable number of relevant technologies was selected. We here use "technology" as an umbrella term covering both individual processes (e.g. the operation of an aircraft), a series of processes within a factory (e.g. manufacturing of steel) and the system of processes required to deliver a product (such as beef) or a service (such as electricity supply) from "cradle" to "gate". The seven consumption categories of Kalbar et al. (2016) all contribute with more than $10 \%$ to the carbon footprint of the average respondent. All categories were therefore considered for the selection of relevant technologies in this study. The narrow categories thermal energy, electricity and air transport were directly adopted as technologies. The more heterogeneous categories of road transport, dwelling and food led to the selection of the additional technologies car transport, steel and cement manufacture and beef and dairy production, which were found to dominate the footprints of those three categories, respectively (data not shown). When comparing these initially selected technologies with the technologies that are used by the industries that contributed the most to the total carbon footprint of Denmark in 2011, according to Exiobase v3, hybrid version (Merciai and Schmidt, 2018), we observed a good agreement, and additionally added transport of goods by ship (which contributes, to varying extends, to all consumption categories of Kalbar (2016)) and public services to the selection. Table 2 presents the ten selected technologies and related modelling information.

Table 2: Relevant technologies and modelling information.

\begin{tabular}{|c|c|c|c|c|c|}
\hline Technology & \begin{tabular}{|l|}
$\begin{array}{l}\text { System } \\
\text { boundary }\end{array}$ \\
\end{tabular} & Spatial scope & Unit* & \begin{tabular}{|l} 
Historic data \\
sources
\end{tabular} & \begin{tabular}{|l}
$\begin{array}{l}\text { Future scenario } \\
\text { sources }\end{array}$ \\
\end{tabular} \\
\hline Steel manufacture & $\begin{array}{l}\text { Manufacturing } \\
\text { plants }\end{array}$ & EU and global & $\mathrm{Kg} \mathrm{CO}_{2} / \mathrm{t}$-crude steel & \begin{tabular}{|l|} 
World Steel \\
Association (2017) \\
\end{tabular} & IEA (2016) \\
\hline $\begin{array}{l}\text { Cement } \\
\text { manufacture }\end{array}$ & $\begin{array}{l}\text { Manufacturing } \\
\text { plants }\end{array}$ & EU and global & $\begin{array}{l}\mathrm{Kg} \mathrm{CO}_{2} / \mathrm{t} \text { white } \\
\text { cement }\end{array}$ & WBCSD (2014) & IEA (2016) \\
\hline $\begin{array}{l}\text { Thermal energy } \\
\text { supply }\end{array}$ & Power plants & Denmark & $\begin{array}{l}\mathrm{Kg} \mathrm{CO}_{2} \text {-eq/GJ district } \\
\text { heating }\end{array}$ & DEA (2015a) & DEA (2015b) \\
\hline Electricity supply & Power plants & Denmark & $\mathrm{Kg} \mathrm{CO}_{2}$-eq/kWh - elec & DEA (2015a) & DEA (2015b) \\
\hline Car transport & Cars & Denmark & Gram $\mathrm{CO}_{2}$-eq/km & DEA (2016a) & DEA (2015b) \\
\hline Air transport & Aircrafts & EU & Gram CO $2 / p-k m$ & IEA (2016) & IEA (2016) \\
\hline $\begin{array}{l}\text { Transport of } \\
\text { goods by ship }\end{array}$ & Ships & Global & Gram $\mathrm{CO}_{2} /$ ton-km & UNCTAD (2016) & IEA (2016) \\
\hline Beef production & Cradle to gate & $\begin{array}{l}\text { Denmark and some } \\
\text { upstream emissions in } \\
\text { other countries }\end{array}$ & $\begin{array}{l}\mathrm{Kg} \mathrm{CO}_{2} \text {-eq/kg dry } \\
\text { matter }\end{array}$ & $\begin{array}{l}\text { Merciai and } \\
\text { Schmidt (2018) }\end{array}$ & This study \\
\hline Dairy production & Cradle to gate & $\begin{array}{l}\text { Denmark and some } \\
\text { upstream emissions in } \\
\text { other countries }\end{array}$ & $\begin{array}{l}\mathrm{Kg} \mathrm{CO}_{2} \text {-eq/kg dry } \\
\text { matter }\end{array}$ & $\begin{array}{l}\text { Merciai and } \\
\text { Schmidt (2018) }\end{array}$ & This study \\
\hline $\begin{array}{l}\text { Supply of public } \\
\text { services }\end{array}$ & Cradle to gate & $\begin{array}{l}\text { Denmark and some } \\
\text { upstream emissions in } \\
\text { other countries }\end{array}$ & $\begin{array}{l}\mathrm{Kg} \mathrm{CO}_{2} \text {-eq } / \$ \text { (constant } \\
\text { prices, PPP) }\end{array}$ & $\begin{array}{l}\text { Merciai and } \\
\text { Schmidt (2018) }\end{array}$ & This study \\
\hline
\end{tabular}

*" $\mathrm{CO}_{2}$ " indicates that $\mathrm{CO}_{2}$ is the only covered GHG, whereas " $\mathrm{CO}_{2}$-eq" indicates coverage of multiple GHGs. 
Bjørn, A., Kalbar, P., Elsborg Nygaard, S., Kabins, S., Jensen, C. L., Birkved, M., Schmidt, J., Hauschild, M. Z. (2018). Pursuing necessary reductions in embedded GHG emissions of developed nations: will efficiency improvements and changes in consumption get us there? Global Environmental Change 52, 314-324. DOI: 10.1016/j.gloenvcha.2018.08.001

Next, historical time series of GHG emission intensities were obtained from external sources for all selected technologies, mainly drawing on statistical agencies, government bodies and industry associations (see Table 2). Supplementary Information 1 documents the construction of the historical time series in a spreadsheet format. For steel and cement manufacture we included both a dataset representing EU and a global dataset. The former is most representative for the consumption of steel in Denmark, while the latter is consistent with the global scope of the corresponding future scenarios (see below).

Finally, we obtained future scenarios of GHG emission intensities for the technologies of Table 2. We aimed for scenarios representing a frozen policy assumption, i.e. assuming that policies currently in place will remain unchanged until 2050. In recognition of the uncertainties of such scenario building, we, to the extent possible, obtained a conservative (low reduction in GHG emissions intensity) and an optimistic (high reduction in GHG emissions intensity) scenario for every technology. For the four technologies at the European and global scales (steel and cement manufacture, air transport and transport of goods by ship, see Table 2), a conservative and an optimistic scenario was obtained from the International Energy Agency (IEA, 2016). The conservative scenario is based on policies currently in place, while the optimistic scenario assumes that all nations will meet their emission pledges in the Paris Agreement through implementation of additional policies. From the model results of these two types of IEA scenarios we calculated GHG emission intensities for four technologies (see Table 2) in 5-year time steps until the year 2050 (dividing total GHG emissions by the corresponding predicted production volumes) and used linear interpolation for the years in between. For thermal energy and electricity supply and car transport, specific to Denmark, the conservative and optimistic GHG emission intensity scenarios of the Danish Energy Agency (DEA, 2015b) were used. Both scenarios reflect a frozen policy assumption, but the optimistic scenario assumes a higher price on $\mathrm{CO}_{2}$ on the European carbon market, the installation of more wind power in Denmark, and a stronger decarbonization of neighboring economies, compared to the assumptions of the conservative scenario. Note that the scenarios obtained for the technologies of Table 2 do not involve any notable contribution from negative emission technologies (NETs) in 2050. This indicates that NETs are unlikely to play a significant role in climate change mitigation under the policies currently in place, which contrasts with the central role they are given in most 1.5 and 2.0 degrees climate scenarios (see Section 2.2). Supplementary Information 1 and 2 provide a detailed documentation of the use of the IEA and DEA scenarios in this study, including their linking to the historic time series. Note that the IEA and DEA scenarios all focus on "hot spots" in the life cycle of goods and services, rather than taking a full life cycle perspective. For some technologies in Table 2, historical data could be obtained for a larger part of their life cycle, but for the sake of consistency, the same system boundaries were used for the historical and future time series for a given technology (see Table 2).

The DEA GHG emission intensity scenarios only extend to the year 2025. Moreover, no suitable scenarios could be identified in the literature for future beef and dairy production or supply of public services. To fill these gaps, we extended the existing scenarios and developed new future scenarios for beef production and supply of public services using exponential regression. For these two technologies only a single future scenario was developed, due to lack of a basis for constructing conservative and optimistic scenarios. We also attempted to develop a future scenario for dairy production, but abandoned the idea because of the strong fluctuations in historical emissions intensities for dairy production, which makes any future projection highly uncertain (see Section 3.1). The development of scenarios is documented in Supplementary Information 1 and 2. Note that the historic and projected emission intensities of the ten selected technologies are averages and that emission intensities vary within each technology, e.g. because of differences in fuel efficiencies between car models for car transport. 
Bjørn, A., Kalbar, P., Elsborg Nygaard, S., Kabins, S., Jensen, C. L., Birkved, M., Schmidt, J., Hauschild, M. Z. (2018). Pursuing necessary reductions in embedded GHG emissions of developed nations: will efficiency improvements and changes in consumption get us there? Global Environmental Change 52, 314-324. DOI : 10.1016/j.gloenvcha.2018.08.001

\section{Results}

\subsection{Personal carbon footprints}

Figure 2 presents the carbon footprints of the 1281 respondents of Kalbar et al. (2016) (left vertical axis).

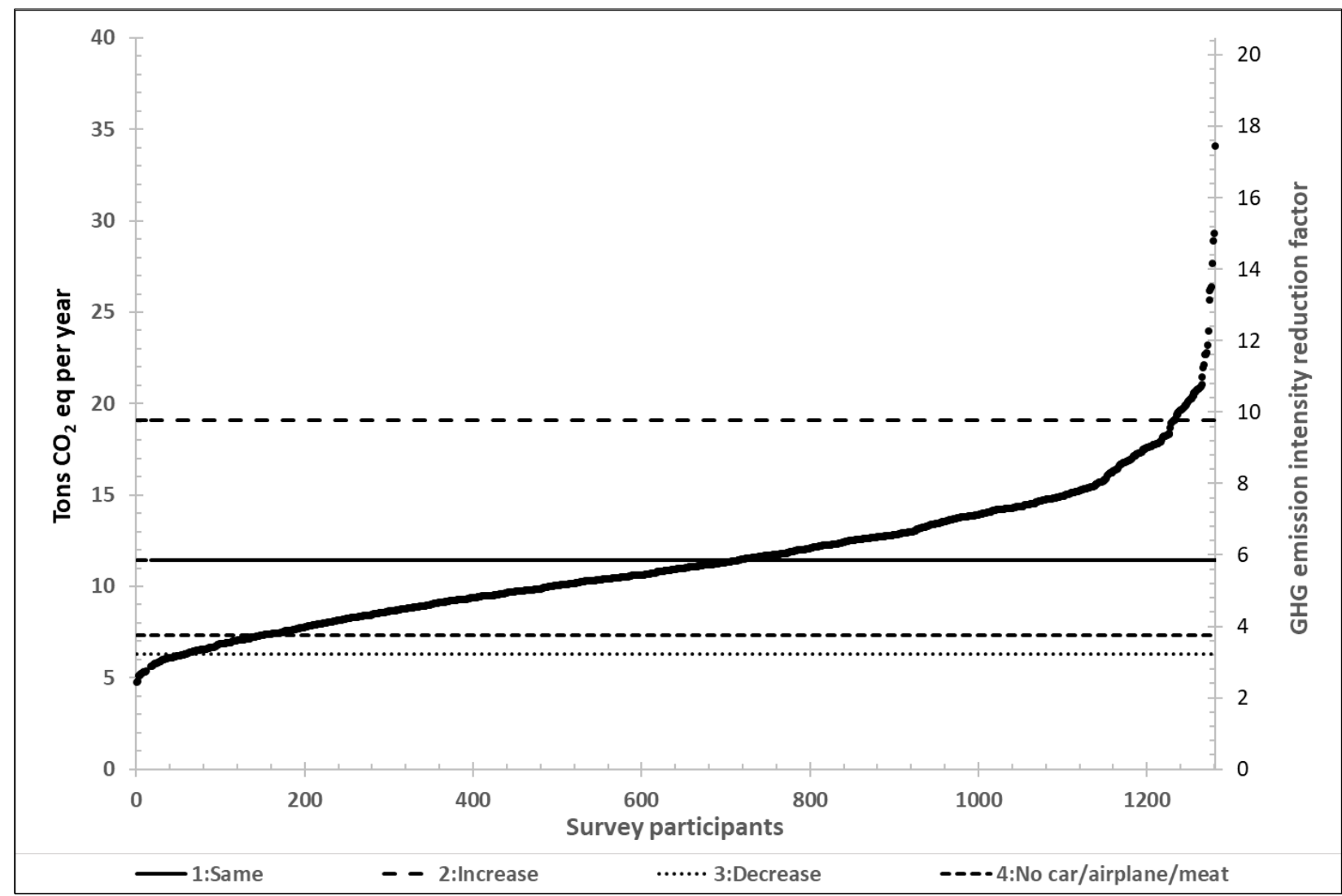

Figure 2: Ranked personal carbon footprints in 2014 from the 1281 respondents of Kalbar et al. (2016). Every dot represents an individual. The four consumption scenarios for 2050 (see Table 1) are indicated with horizontal lines. The right-hand vertical axis shows the factor by which the average GHG emission intensity across all technologies must be reduced to meet a 2050 emission target of $\mathbf{2 . 0}$ tons $\mathrm{CO}_{2}$-eq per capita, which is consistent with the $\mathbf{2 . 0}$ degrees climate goal (medium global GHG emission budget and population estimates. Additional reduction factors are listed in Table 3.

The average respondent was found to have a carbon footprint of 11.4 tons $\mathrm{CO}_{2}$-eq in 2014 . This is much lower than the 18.7 tons $\mathrm{CO}_{2}$-eq per capita calculated using the Exiobase v3 hybrid 10 database (Merciai and Schmidt, 2018) for the average Danish resident in the year 2011. The reason for this difference is discussed in Section 4.1. The extreme low and high personal annual footprints were found to span an interval of 5-34 tons $\mathrm{CO}_{2}$-eq per year. The four consumption scenarios for 2050 are also indicated on Figure 2 and their associated current carbon footprints are broken up into contributions from categories of goods and services in Figure 3. 
Bjørn, A., Kalbar, P., Elsborg Nygaard, S., Kabins, S., Jensen, C. L., Birkved, M., Schmidt, J., Hauschild, M. Z. (2018). consumption get us there? Global Environmental Change 52, 314-324. DOI: 10.1016/j.gloenvcha.2018.08.001

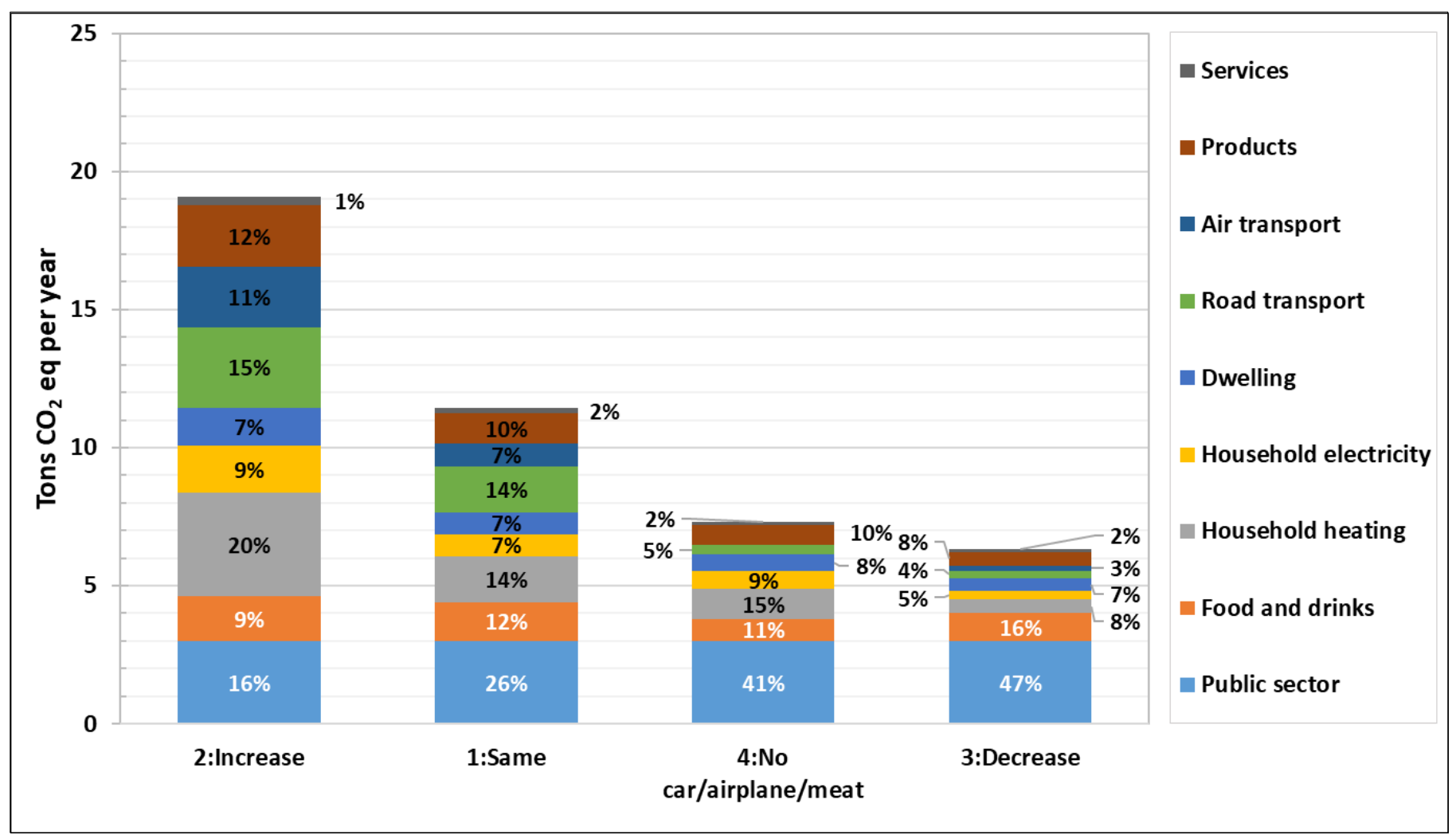

Figure 3: Composition of personal carbon footprints for the four consumption scenarios.

It can be seen that the footprint components' absolute contributions to personal carbon footprints differ substantially across scenarios. The difference between highest and lowest contribution is largest for household district heating ( 3.3 tons $\mathrm{CO}_{2}$-eq difference), road transport ( 2.6 tons $\mathrm{CO}_{2}$-eq difference) and air transport (2.2 tons $\mathrm{CO}_{2}$-eq difference). This suggests that these components should receive high attention in the design of sustainable consumption policies (see Section 4.3.2). Note also that the contribution from the public sector amounts to almost $50 \%$ of the lowest current personal carbon footprints. This shows that consumption reduction in the public sector also can be an important lever for the reduction in per capita footprints, as further discussed in Section 4.2.

\section{Required reductions of GHG emission intensities}

The right-hand vertical axis of Figure 2 presents, for the different carbon footprints (left vertical axis), the GHG emission intensity reduction factors that are required by the year 2050 to meet the per capita emission target based on the 2.0 degrees climate goal. A factor 10 reduction is required for Scenario 2:Increase. So if all inhabitants of Denmark by the year 2050 were to exhibit the consumption pattern of the highest tenth percentile of the population surveyed by Kalbar et al. (2016), the technologies used to deliver the consumed goods and services must, on average, increase their efficiencies 10 times. In contrast, Scenario 3:Decrease, reflecting the most ambitious changes towards low-carbon consumption, only requires a factor 3 reduction in the average GHG emission intensity of technologies. Hence, Figure 2 shows that variations in the conceivable future consumption pattern of a population can greatly influence the potential to meet climate targets for national consumption.

By comparison, Girod et al. (2013) estimated that a factor 5 reduction in GHG emission intensities in the production of goods and services globally would be needed in 2050, compared to 2010, to meet the 2.0 
Bjørn, A., Kalbar, P., Elsborg Nygaard, S., Kabins, S., Jensen, C. L., Birkved, M., Schmidt, J., Hauschild, M. Z. (2018). Pursuing necessary reductions in embedded GHG emissions of developed nations: will efficiency improvements and changes in consumption get us there? Global Environmental Change 52, 314-324. DOI: 10.1016/j.gloenvcha.2018.08.001

degrees climate goal, when assuming a "consumption as usual" development in all regions of the world. This estimate is closest to the requirement found in this study for Scenario 1:Same (see Figure 2).

Thus, if the global development in living standards is to follow current trends, then the required reduction in the GHG emission intensity of global production is around the same as the required emission intensity reduction of the production that is satisfying a Danish consumption stabilized at current levels.

In addition to the reduction factors in Figure 2, Table 3 shows reduction factors for the 1.5 degrees climate goas for the four consumption scenarios. The table also shows low and high reduction factors for both climate goals, derived from combinations of low and high estimates of the global population and GHG emission budget in 2050 (see Section 2.2).

Table 3: GHG emission intensity reduction factors for all combinations of consumption scenarios, climate goals and modelling estimates. Low = low population and high GHG emission budget; Medium = medium population and medium GHG emission budget; High = high population and low GHG emission budget.

\begin{tabular}{|l|l|l|l|l|}
\hline & 1:Same & 2:Increase & 3:Decrease & $\begin{array}{l}\text { 4:No car/ } \\
\text { airplane/meat }\end{array}$ \\
\hline 2.0 degrees goal, low & 3.7 & 6.2 & 2.0 & 2.4 \\
\hline 2.0 degrees goal, medium & 5.8 & 9.8 & 3.2 & 3.7 \\
\hline $\mathbf{2 . 0}$ degrees goal, high & 7.3 & 12.1 & 4.0 & 4.6 \\
\hline $\mathbf{1 . 5}$ degrees goal, low & 6.2 & 10.4 & 3.4 & 4.0 \\
\hline $\mathbf{1 . 5}$ degrees goal, medium & 8.5 & 14.3 & 4.7 & 5.5 \\
\hline $\mathbf{1 . 5}$ degrees goal, high & 20.6 & 34.3 & 11.4 & 13.2 \\
\hline
\end{tabular}

\subsection{Past and future GHG emission intensities of relevant technologies compared to targets}

Figure 4 presents GHG emission intensity time series for the ten technologies that were found to have high contributions to the carbon footprint of the average respondent of Kalbar et al. (2016) (see Table 2), and also the reduction targets for the year 2050 corresponding to the four explorative consumption scenarios (see Table 1).

The historic time series for the ten technologies of Figure 4 end in 2011-2015. After the last year of historic data, scenarios account for the developments until the year 2050. Dashed and dotted graphs in Figure 4 indicate, respectively, scenarios adopted from literature and scenarios constructed in this study (details in Supplementary Information 1 and 2). The four target intervals for 2050 are based on inversions of the GHG emission intensity reduction factors of Table 3. Each of the 2050 target intervals for the four consumption scenarios span the variations in temperature goal (2.0 or 1.5 degrees) and modelling estimates of population (low, medium, high) and $2050 \mathrm{GHG}$ emission budgets (high, medium, low). For example, the interval for Scenario 3:Decrease was calculated as $1 / 11.4$ to $1 / 2.0=0.09$ to 0.49 (see Table 3).

Figure 4 offers the following interpretation: if the population of Denmark in 2050 on average will be having the consumption pattern of one of the four consumption scenarios, then the future GHG emission intensities will be required to decrease to the 2050 target interval for that consumption scenario, in order for the per capita GHG emission to be aligned with one or more climate goals. Note that the 2050 GHG emission intensity target intervals of Figure 4 apply to all the technologies involved in the delivery of the goods and services consumed by the Danish population, amongst which the ten selected technologies 
Bjørn, A., Kalbar, P., Elsborg Nygaard, S., Kabins, S., Jensen, C. L., Birkved, M., Schmidt, J., Hauschild, M. Z. (2018). Pursuing necessary reductions in embedded GHG emissions of developed nations: will efficiency improvements and changes in consumption get us there? Global Environmental Change 52, 314-324. DOI : 10.1016/j.gloenvcha.2018.08.001

covered by Figure 4 have especially high contributions to carbon footprints. We do not propose that all technologies must reduce their GHG emission intensities by the same factor, since reductions are expected to be more economically feasible for some technologies than for others (Girod et al., 2013; IEA, 2016). Therefore, the 2050 emission targets may be met even if some of the selected technologies covered by Figure 4 fail to meet an emission intensity target interval, provided that other technologies achieve an even higher reductions in emission intensity than the target interval. 
Bjørn, A., Kalbar, P., Elsborg Nygaard, S., Kabins, S., J ensen, C. L., Birkved, M., Schmidt, J., Hauschild, M. Z. (2018). Pursuing necessary reductions in embedded GHG emissions of developed nations: will efficiency improvements and changes in consumption get us there? Global Environmental Change 52, 314-324. DOI:

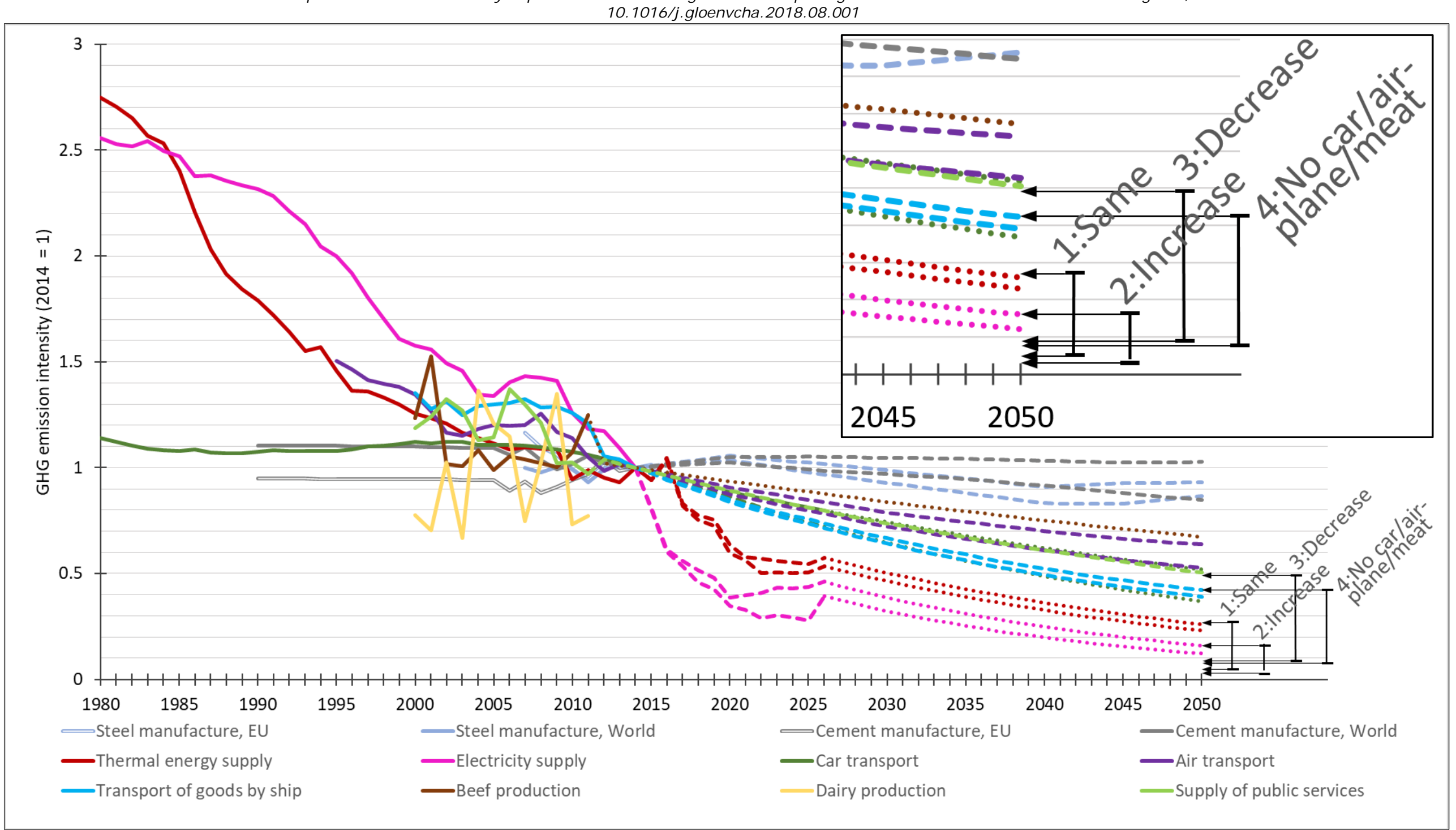

Figure 4: GHG emission intensities for ten selected technologies (Table 2) and 2050 target intervals for each of the four consumption scenarios. Historic time series are solid, future scenarios adopted from the literature are dashes, and future scenarios developed in this study are dotted. For the majority of the technologies, both a conservative (low reduction of GHG emission intensity) and an optimistic (high reduction of GHG emission intensity) scenario are shown. 2050 targets for each consumption scenario are shown as intervals, spanning over the two temperature goals and low to high modelling estimates (see Table 3). The bottom right corner of the graph is magnified in the top right corner. 
Bjørn, A., Kalbar, P., Elsborg Nygaard, S., Kabins, S., Jensen, C. L., Birkved, M., Schmidt, J., Hauschild, M. Z. (2018).

Pursuing necessary reductions in embedded GHG emissions of developed nations: will efficiency improvements and changes in consumption get us there? Global Environmental Change 52, 314-324. DOI: 10.1016/j.gloenvcha.2018.08.001

It is apparent from Figure 4 that the GHG emission intensities of many of the displayed technologies have decreased steadily over past decades, while the intensity for some technologies, such as transport by car and cement manufacture (both in EU and globally) have been rather constant. For some technologies the historic developments in GHG emissions intensities show strong fluctuations, most notably for beef and dairy production. For these two technologies the fluctuations are largely caused by interannual variations in sourcing locations for fodder, crop yields and fertilizer and pesticide use, caused by climatic variations.

The GHG emission intensities of technologies are projected to decrease in most future scenarios (dashed or dotted graphs). The projected decreases vary substantially between technologies with the 2050 GHG emission intensity of Danish electricity supply projected to be less than $20 \%$ of its 2014 value, while the 2050 intensity for steel manufacture is projected to be around $90 \%$ of its 2014 value. By comparison, the 2050 GHG emission intensity of an average unit of production (constant prices, purchase power parity corrected) is projected to decrease to $38-50 \%$ of its 2014 value, according to the optimistic and conservative scenarios of IEA (2016) (see Supplementary Information 1). The emission intensities of most time series (historic data and scenarios) decrease with time in accordance with an exponential development, which indicates potential limits to efficiency gains, under the assumed frozen policy regimes. However, it must be noted that there is a large difference between potential efficiency gains within the current economic regime and the gains that are technologically feasible. Cullen et al. (2011), for example, estimated that the global energy demand could be reduced by $73 \%$ (46-98\% across technologies) by applying engineering options already known. This energy reduction potential translates into an even larger GHG emission reduction potential, considering the effect of switching from high to low emission intensive energy provision technologies.

Figure 4 shows that the GHG emission intensities of four of the ten technologies are projected to meet the intensity target interval for Scenario 3:Decrease, while only one technology, electricity supply, is projected to meet the (upper part of) the intensity target interval for the Scenario 2:Increase. This demonstrates that the consumption pattern of the future Danish population has a strong influence on the extent to which the environmental policies that are currently in place are projected to be sufficient. Also, it can be seen that no technology reaches the lower target interval boundary for any of the four consumption scenarios, which correspond to the 1.5 degrees temperature goal with a high global population projection and a low GHG emission budget estimation. This shows that uncertainties in the derivation of the 2050 climate targets also greatly influences whether the combined effects of improving technological efficiencies and conceivable changes in consumption patterns can be considered sufficient to meet these targets.

\section{Discussion}

In this section, we first propose how uncertainties and methodological shortcomings may be reduced to better answer the research question of this paper. We then address the policy implications of our findings. 
Bjørn, A., Kalbar, P., Elsborg Nygaard, S., Kabins, S., Jensen, C. L., Birkved, M., Schmidt, J., Hauschild, M. Z. (2018).

Pursuing necessary reductions in embedded GHG emissions of developed nations: will efficiency improvements and changes in consumption get us there? Global Environmental Change 52, 314-324. DOI: 10.1016/j.gloenvcha.2018.08.001

\subsection{Limitations of study and potentials for improvement}

This study found an average carbon footprint of 11.4 tons $\mathrm{CO}_{2}$-eq per year for the survey respondents of Kalbar et al. (2016) in 2014. This is $39 \%$ lower than the 18.7 tons $\mathrm{CO}_{2}$-eq per capita per year for Denmark in 2011, which is the most recent estimate based on EEIO analysis, in the form of the Exiobase v3 hybrid IO database (Merciai and Schmidt, 2018). The 18.7 tons may be somewhat overestimated, because the contribution from the Danish "Sea and coastal water transport" industry amounts to almost 1 ton $\mathrm{CO}_{2}$ eq per year, which is clearly an overestimation. Still, the main explanation for the discrepancy between the average personal carbon footprint derived in this study and the Exiobase estimate is likely that the former is underestimated: First, even though invitations to participating in the online survey of Kalbar et al. (2016) was distributed to around 16,000 households in different parts of Denmark, the 1281 respondents may not be representative of the entire Danish population. This is because the time and effort required to answer the survey may have caused environmentally conscious individuals to be overrepresented. This type of response bias is difficult to avoid when gathering self-reported environmental data. Another source of underestimation may be our choice of calculating footprints using a process-based approach to inventorying life cycle emissions. This approach is, with few documented exceptions (see e.g. Goldstein et al. (2017)), known to underestimate environmental impacts. This is due to the practice of "cutting off" from the system boundaries the parts of the supply chains of goods and services, which are judged to, individually, have negligible effects on the total footprint and for which process data are difficult to obtain (Kalbar et al., 2016). Future studies may eliminate this cause of underestimation by using EEIO analysis to model footprints based on personal expenditure on different goods and services, but this would likely come at the cost of less detailed modelling of technologies than in the process-based approach taken here. Yet, EEIO models are developing towards higher product- and industry granularity and higher geographical resolution and is thus expected to become a more viable alternative to the process-based approach.

Our study focuses on trends in the GHG emission intensities of a subset of technologies, which had high contributions to the personal carbon footprints amongst the survey respondents, and compares these trends to the emission intensity reduction that is required to meet climate targets for the different consumption scenarios. This gives important insights as to whether key technologies are "on track" towards meeting these requirements. However, it must be noted that, for most technologies, different data sources had to be used to construct historical and future time series. This constitutes a risk of inconsistencies between system boundaries and data generation and modelling procedures (see Supplementary Information 1 and 2). If the developers of future scenarios (e.g. IEA) would disclose the historic time series that they have used to construct future scenarios, more internally consistent time series of GHG emission intensities could be developed and used to improve future studies similar to this.

In our study, the construction of future consumption scenarios was based on observed variations between personal carbon footprints within the current population. Compared to the creation of hypothetical scenarios, this approach has the advantage that scenarios are based on consumption patterns of actual groups of people (Girod and de Haan, 2009) and hence represent consumption patterns that are possible today. Yet, the approach also has drawbacks. First, it does not consider the level of well-being associated with different consumption patterns. To ensure that a low emission level does not come at the cost of unacceptable reductions in well-being, the approach of Druckman and Jackson (2010) could be taken. They constructed a consumption scenario based on a minimum 
Bjørn, A., Kalbar, P., Elsborg Nygaard, S., Kabins, S., Jensen, C. L., Birkved, M., Schmidt, J., Hauschild, M. Z. (2018).

Pursuing necessary reductions in embedded GHG emissions of developed nations: will efficiency improvements and changes in consumption get us there? Global Environmental Change 52, 314-324. DOI: 10.1016/j.gloenvcha.2018.08.001

acceptable material standard of living, which was derived through a "consensual discussion" amongst citizens informed by expert inputs. Such a minimum standard is likely to change over time (Gough, 2017) (see also Section 4.3.2) and may therefore be complemented by the techniques of Spurling and Kuijer (2016) and Spurling and Jensen (2017) to imagine radically different future consumption patterns.

Our study disregards the connections between income and personal carbon footprints. Environmental impacts generally correlate well with income (Girod et al., 2013; Girod and de Haan, 2009). The average income of the respondents that Scenario 3:Decrease is based on is therefore likely to be lower than the average income of all respondents (corresponding to Scenario 1:Same) (Girod and de Haan, 2009). Since people tend to spend, rather than accumulate, their income, it is unrealistic to expect the entire population to follow the consumption pattern of Scenario 3:Decrease. Future studies could design consumption scenarios to have equal average expenditure, using a technique inspired by Girod and de Haan (2009). A low emission scenario would then be characterised by the consumption of goods and services having a low GHG emission per unit of cost (such as art or domestic help). Identifying such consumption patterns is furthermore important, considering the risk of the rebound-effect, which occurs when an efficiency-improvement in the delivery of a good or service results in a cost saving to the user, which consequently lead to in an increased consumption of this or other goods or services (Chitnis et al., 2013; Sorrell, 2015).

\subsection{Policy implications}

Figure 4 shows that current policies are insufficient in ensuring that Denmark will stay within its "fair share" of a global GHG emission budget in 2050. The degree of insufficiency is likely to be even greater than shown in Figure 4, considering this study's underestimation of the current per capita carbon footprint (see Section 4.1) and considering that the target intervals for emission intensities are somewhat artificially high, since they are derived from scenarios involving an unrealistically high climate change mitigation from NETs (see Section 2.2). Further, our study suggests that neither the technology nor the consumer lever, by itself, is adequate: Even a large divergence from a "consumption as usual" development (Scenario 3:Decrease or 4:No meat/airplane/car) would, by itself, be insufficient in meeting climate targets for more than half of the ten selected technologies under current policies. Likewise, if consumption is to follow a "consumption as usual" development (as per Scenario 2:Increase), then an annual average decarbonization across technologies of 5-9\% (depending on the climate goal, population projections and estimated global GHG budget) would be required (data not shown). This requirement is likely unachievable, even if a large divergence from "business as usual" in technological innovation were to take place, considering that the historic annual average decarbonization rate of the ten technologies covered by Figure 4 was just $1.2 \%$ (varying between $-0.2 \%$ for cement manufacture and 3.0\% for thermal energy supply). Our findings are likely to be valid for most developed nations, given that the per capita carbon footprint of Denmark has been found to be close to the OECD average (Ivanova et al., 2015; Wood et al., 2018). Our findings are also in agreement with the finding of de Koning et al. (2016), who uses EEIO analysis to predict that even a large-scale implementation of low-carbon technologies, including NETs, at the global level will be insufficient in meeting a 2050 emission target based on the 2.0 degrees climate goal, if this is not accompanied by a large divergence from "consumption as usual". 
Bjørn, A., Kalbar, P., Elsborg Nygaard, S., Kabins, S., Jensen, C. L., Birkved, M., Schmidt, J., Hauschild, M. Z. (2018).

Pursuing necessary reductions in embedded GHG emissions of developed nations: will efficiency improvements and changes in consumption get us there? Global Environmental Change 52, 314-324. DOI: 10.1016/j.gloenvcha.2018.08.001

Several related studies have pointed out large gaps between frozen policy based GHG emission projections and emission pledges of many nations on one side and, on the other side, emission levels that would be aligned with climate goals (Rogelj et al., 2016; UNEP, 2015). These existing studies take a territorial approach in emission accounting and target setting, following the accounting procedure of United Nations Framework Convention on Climate Change (UNFCC). Our study complements such studies by using consumption-based accounting (i.e. covering emissions across supply chains, no matter where they occur) in the study of gaps between emission trends and targets. Considering that GHG emissions embedded in trade are globally increasing (both in absolute terms and relative to total emissions) (Wood et al., 2018), consumption-based accounting can be seen as an increasingly important complement to territorial accounting in the context of policies aiming to meet climate targets.

Below, we take point of departure in the Danish policy context to discuss in greater details what our findings mean for technology-oriented climate policies. We then discuss how consumer-oriented policies may help to realize Scenario 3:Decrease or even more radical downward changes in consumption. Policies for restricting population growth are not explicitly considered, but it can be noted that they could potentially allow for a modestly higher 2050 per capita GHG emission budget: If the global population was to (hypothetically) stabilize at its 2014 level, the 2050 per capita emission budget (medium climate model estimates) would be 1.8 and 2.6 tons $\mathrm{CO}_{2}$-eq for the 1.5 and 2.0 degrees warming scenarios, respectively, instead of the 1.3 and 2.0 tons $\mathrm{CO}_{2}$-eq that correspond to the medium population projection of UN (2015) (data not shown).

\subsubsection{The role of existing and new technology- and consumer-oriented policies}

The Danish government, at the time of writing, has set a goal for 2050 to become "independent on fossil fuels" (DEA, 2016b). Meeting this goal would require new technology-oriented climate policies (Sørensen et al., 2015), such as taxes on fossil fuels or $\mathrm{CO}_{2}$ emissions, legal emission limits on technologies and favorable conditions for the development and mainstreaming of new low-carbon technologies (Girod et al., 2013). Independence of fossil fuels could mean close to zero emissions of $\mathrm{CO}_{2}$ from the Danish territory, with potential cement production being the only significant source. According to the Exiobase $v 3$ hybrid 10 database (Merciai and Schmidt, 2018) zero territorial $\mathrm{CO}_{2}$ emissions would mean, all other things being equal, a 33\% reduction in the carbon footprint of Denmark in 2050, from 18.7 to 12.4 tons $\mathrm{CO}_{2}$-eq per capita. This reduced potential carbon footprint is still much higher than the targets derived in this study of 0.6-3.1 tons $\mathrm{CO}_{2}$-eq per capita, see Section 2.2. GHG emissions could be reduced further by additional domestic regulation aiming to restrict $\mathrm{CH}_{4}$ and $\mathrm{N}_{2} \mathrm{O}$ emissions from agriculture. However, as for many other developed nations, more than half (58\%) of the Danish carbon footprint originated abroad in 2011 (Merciai and Schmidt, 2018). Therefore, when a developed nation, such as Denmark, only sets reduction target for territorial emissions, it means that the majority of the emissions caused by its consumption is potentially uncovered by the target. If individual nations were to take full responsibilities for embedded emissions abroad, trade barriers against emission intensive products, through a mechanisms of "border carbon adjustment" (Kokoni and Skea, 2014), would be an option. Another approach would be to reduce emission intensities globally in a coordinated fashion through international policy frameworks, such as UNFCCC. With regards to consumption in the public sector, which has a substantial contribution to the total Danish footprint (see Figure 3), $65 \%$ of it was found to originate abroad (Merciai and Schmidt, 2018). This share may be reduced by including emission limits as criteria for the state's procurement of products and services. 
Bjørn, A., Kalbar, P., Elsborg Nygaard, S., Kabins, S., Jensen, C. L., Birkved, M., Schmidt, J., Hauschild, M. Z. (2018).

Pursuing necessary reductions in embedded GHG emissions of developed nations: will efficiency improvements and changes in consumption get us there? Global Environmental Change 52, 314-324. DOI: 10.1016/j.gloenvcha.2018.08.001

With respect to consumer-oriented policies, the results of this study indicate that large changes in present consumption trends will be needed to meet the per capita 2050 climate targets. This calls for policies that effectively drive low-carbon consumption patterns. According to neoclassical economic theory, policies aiming to correct market externalities (e.g. through energy taxes) affect consumers in addition to producers, since price effects will incentivize a lower demand for emission-intensive products. However, such policy measures have often turned out to be less efficient than predicted by economic models due to "behavioral market failures", i.e. people not behaving economically rational in response to market signals (Creutzig et al., 2018). Girod et al. (2014) discuss a range of complementary policy measures (e.g. product labeling, nudging and education) that aim to influence individuals to choose the least emission intensive option for satisfying a given need. Such policy measures have all, in varying extent, been implemented in Denmark throughout the last decades. Still, the nation's per capita carbon footprint in the period 2000-2011 has been quite stable at a high level of 19-22 tons $\mathrm{CO}_{2}$-eq per year with only a minor decreasing trend over the entire period, according to Exiobase v3 (Merciai and Schmidt, 2018) (the study of (Wood et al., 2018) finds a similar trend). This implies that, during this period, the combined effect of any changes towards the consumption of goods and services with relatively low GHG emission intensities (such as energy efficient light bulbs) and the gradual GHG emission intensity reductions of various technologies (such as electricity supply) (see Figure 3 ) has been roughly cancelled out by an increase in consumption (combined with increases in GHG emission intensities associated with the outsourcing of some manufacture to regions like China, as discussed in Herrmann and Hauschild (2009)). Ironically, this increase in consumption may in part have been caused by a decrease in GHG emission intensities due to the rebound effect (see Section 4.1). The unfortunate stability of the per capita carbon footprint over the past decade suggests that there is a limit to how much existing sustainable consumption policies can take us towards radical reductions in carbon footprints, as also argued by Akenji (2014) and Gjerris et al. (2016).

\subsubsection{Beyond understanding consumption as a matter of individual choices}

It has been argued that to be effective, policies need to shift their scope from focusing only on the consumption choices of individuals to also considering social and institutional dimensions of consumption (Jensen, 2017; Spurling et al., 2013). Scholars of sustainable consumption are increasingly raising questions about how changes within complex socio-technical systems come about, and a palette of theories of social change are available for such inquires (Creutzig et al., 2018; Fuchs et al., 2016). Amongst these, theories of practice seem particularly relevant for understanding consumption beyond conscious purchasing decisions of individuals. In their everyday life, people engage in several social practices that give meaning to consumption. People cook, eat, shop and work, etc. and it is through the reproduction of these practices and their interactions, that certain levels of consumption are maintained as part of what is considered a "need" or "normal" (Røpke, 2009; Jensen, 2017). However, social conventions for what is considered normal can change. Shove (2003), for example, discusses how social conventions surrounding comfort (e.g. a pleasant indoor temperature), cleanliness (e.g. showering) and convenience (e.g. easing cooking via freezers and microwave ovens) historically have evolved towards more resource-intensive practices. Shove (2003) argues that this increase in consumption of resources (e.g. energy and water) has come about not as a result of individuals deliberately choosing to consume more, but through gradual and non-deliberate changes in practices such as showering and doing laundry more often. 
Bjørn, A., Kalbar, P., Elsborg Nygaard, S., Kabins, S., Jensen, C. L., Birkved, M., Schmidt, J., Hauschild, M. Z. (2018).

Pursuing necessary reductions in embedded GHG emissions of developed nations: will efficiency improvements and changes in consumption get us there? Global Environmental Change 52, 314-324. DOI: 10.1016/j.gloenvcha.2018.08.001

Practices thus play a role in stabilizing certain consumption patterns, but also in their gradual evolution, unfortunately often towards more resource-intensive patterns. However, the very recognition that human actions are socially and institutionally embedded may be used to design policies that can help bring about the radical change in consumption that this study suggests is required. Below, we present some illustrative findings and policy implications from studies taking a selection of practice theory perspectives on household heating and road and air transport. These three footprint components were chosen because they differ greatly across respondents (see Figure 3 ). Different practices affecting these three footprint components are therefore important to understand for better policy design.

In a study of five Danish families, living in similar houses and relying on the same district heating sources, Gram-Hanssen (2010) analyze how different practices of indoor climate regulation may explain large differences in the annual heat consumption of the families. These practices are explored and described through four elements and their interconnections: technology (building layout, ventilation and heating system), habits (e.g. from upbringing or experiences), knowledge (e.g. information from health authorities on avoiding allergies or from the district heating utility on how to save money) and meaning (e.g. environmental concerns, creation of a cozy atmosphere or satisfaction in operating technologies optimally). These components may to different extends be influenced by policies in the effort of changing practices towards lower heat consumption, and to be effective, policies must consider all components of practices, as further discussed in Laakso et al. (2017).

Transportation can both be seen a practice in itself and as "cement" that allows for people to carry out a series of practices across space within a short timespan (Laakso, 2017). Studies that understand transportation as a practice in itself often try to understand the practice of conventional oil-based car driving and those of alternative and less GHG emission intensive modes of transportation. A study of electric vehicle users in Norway suggests that a shift from conventional cars depend less on elements of technology (e.g. availability of charging infrastructure) and more on elements of competence (e.g. getting hands-on experience by borrowing an electric vehicle from a friend) and on meaning (e.g. signaling of pro-environmental behavior) (Ryghaug and Toftaker, 2014). Spurling et al. (2013) discuss how a shift from car to bike commuting in the UK may be induced and highlight the Greater Manchester's Cycling Hub scheme as an example of a policy intervention that shows understanding of transportation practices. The scheme offers the material elements of safe, indoor bike parking close to public transit and access to showers (accommodating the cultural expectation of cleanliness at work) and also offers an element of competence through training in biking and bike repair skills offered to citizens. Studies seeing transportation as the "cement" holding other practices together often focus on how (changes in) these other practices may enable or prevent a change in transportation. Laakso (2017) studied a Finnish experiment, in which families who had sold a car (not necessarily being their only car) received a six month public transportation pass for free. The different modes of transport taken up, as well as differences in travel distance and changes in other practices were studied. The authors concluded that everyday transport and the other practices they enable have a strong element of routine and that new transport practices therefore are most likely to take place under life-changing circumstances. Conversely, the author suggested that policies encouraging low-carbon transportation could offer free public transportation for a limited time to people changing address, thus exploiting a window of opportunity where emission-intensive practices have not yet become routine. 
Bjørn, A., Kalbar, P., Elsborg Nygaard, S., Kabins, S., Jensen, C. L., Birkved, M., Schmidt, J., Hauschild, M. Z. (2018).

Pursuing necessary reductions in embedded GHG emissions of developed nations: will efficiency improvements and changes in consumption get us there? Global Environmental Change 52, 314-324. DOI: 10.1016/j.gloenvcha.2018.08.001

While road transport is generally a mundane part of everyday life, air travel is predominantly used as a break from everyday life (Aguiléra, 2014). Many young people are taking a whole year off everyday life. Luzecka (2016) found that an individual's decision to do a "gap year" that involves a lot of long-haul air travel between several continents (i.e. emitting lots of $\mathrm{CO}_{2}$ ) to a large extent is influenced by other actors, such as non-governmental organizations (NGO) running volunteering programs abroad, parents, teachers, (future) employers and university admission tutors. Common for these actors is the positive meaning they attach to a long-haul intensive gap year, which is believed to build character and show initiative, and thereby help young people appear attractive on the job and university markets. Accordingly, policy interventions aiming to reduce GHG emissions associated with a gap year should target these influential actors (Luzecka, 2016). For example, NGOs could be persuaded to increase the promotion of domestic volunteering projects, e.g. in poor communities, to help attach the same positive meaning of personal development to gap year activities closer to home. Meaning has also found to be an important element to understand the increasing practice of long-haul leisure flights amongst pensioners. Fox et al. (2017) interviewed a group of pensioners who associated long-haul travel with novelty (especially when going to non-western destinations) and with opportunity to display ability and an active later life. To bend the long-haul travel trend, promoters of "staycation" could therefore propose ways in which novelty can be enjoyed and capability displaied closer to home.

\section{Conclusion}

Our study demonstrates the importance of combining a technology- and consumer perspective when addressing the broad question of how societies can develop within finite environmental carrying capacities. Firstly, we show that the efficiency increase in the production of goods and services that is necessary to avoid exceeding climate goals, greatly depends on the future development in demands for these goods and services. Secondly, our results strongly indicate that a "development as usual" pathway for either technological innovation or consumption will make it impossible for a developed nation to meet climate targets based on humanity's equitable sharing of a global GHG emission budget. This call for additional studies that explore how a combination of radical, but imaginable, divergence from existing trends in technological development and in consumption can deliver the required deep cuts in national carbon footprints.

\section{Acknowledgements}

We thank Rasmus Hauschild for graphic design and layout of Figure 1 and three anonymous reviewers for their useful comments.

\section{Supplementary Information}

Supplementary Information 1 is a spreadsheet containing the data of the time series and their sources and calculations used in this study. Supplementary Information 2 presents the procedure for how historic and scenario time series were joined and explains how exponential regression was used to develop additional scenarios in this study.

\section{References}

Aguiléra, A., 2014. Business Travel and Sustainability, in: Gärling, T., Ettema, D., Friman, M. (Eds.), Handbook of Sustainable Travel. Springer. 
Bjørn, A., Kalbar, P., Elsborg Nygaard, S., Kabins, S., Jensen, C. L., Birkved, M., Schmidt, J., Hauschild, M. Z. (2018). Pursuing necessary reductions in embedded GHG emissions of developed nations: will efficiency improvements and changes in consumption get us there? Global Environmental Change 52, 314-324. DOI: 10.1016/j.gloenvcha.2018.08.001

Akenji, L., 2014. Consumer scapegoatism and limits to green consumerism. J. Clean. Prod. 63, 13-23.

Association Ecoinvent, 2018. ecoinvent. Available: http://www.ecoinvent.org/ (accessed 4.20.18).

Chitnis, M., Sorrell, S., Druckman, A., Firth, S.K., Jackson, T., 2013. Turning lights into flights: Estimating direct and indirect rebound effects for UK households. Energy Policy 55, 234-250.

Creutzig, F., Roy, J., Lamb, W.F., Azevedo, I.M.L., de Bruin, W.B., Dalkmann, H., Edelenbosch, O.Y., Geels, F.W., Grübler, A., Hepburn, C., Hertwich, E., Khosla, R., Mattauch, L., Minx, J.C., Ramakrishnan, A., Rao, N., Steinberger, J., Tavoni, M., Ürge-Vorsatz, D., Weber, E.U., 2018. Towards demand-side solutions for mitigating climate change. Nat. Clim. Chang. 8, 268-271.

Cullen, J.M., Allwood, J.M., Borgstein, E.H., 2011. Reducing energy demand: What are the practical limits? Environ. Sci. Technol. 45, 1711-1718.

de Koning, A., Huppes, G., Deetman, S., Tukker, A., 2016. Scenarios for a $2{ }^{\circ} \mathrm{C}$ world: a trade-linked input-output model with high sector detail. Clim. Policy 16, 301-317.

DEA, 2016a. Personal communication with Andreas Moltesen, Danish Energy Agency.

DEA, 2016b. Dansk klimapolitik. Danish Energy Agency. Available: https://ens.dk/ansvarsomraader/energi-klimapolitik/fakta-om-dansk-energi-klimapolitik/danskklimapolitik (accessed 4.20.18).

DEA, 2015a. Energistatistik 2015. Danish Energy Agency.

DEA, 2015b. Danmarks Energi- og Klimafremskrivning 2015. Energistyrelsen (Danish Energy Agency), Denmark.

Druckman, A., Jackson, T., 2010. The bare necessities: How much household carbon do we really need ? Ecol. Econ. 69, 1794-1804.

Fanning, A.L., O'Neill, D.W., 2016. Tracking resource use relative to planetary boundaries in a steadystate framework: A case study of Canada and Spain. Ecol. Indic. 69, 836-849.

Fox, E., Hitchings, R., Day, R., Venn, S., 2017. Demanding distances in later life leisure travel. Geoforum 82, 102-111.

Fuchs, D., Di Giulio, A., Glaab, K., Lorek, S., Maniates, M., Princen, T., Røpke, I., 2016. Power: the missing element in sustainable consumption and absolute reductions research and action. J. Clean. Prod. 132, 298-307.

GFN. Global Footprint Network, 2016. Footprint Calculator. Available: https://www.footprintnetwork.org/resources/footprint-calculator/ (accessed 4.20.18).

Girod, B., de Haan, P., 2009. GHG reduction potential of changes in consumption patterns and higher quality levels: Evidence from Swiss household consumption survey. Energy Policy 37, 5650-5661.

Girod, B., van Vuuren, D.P., Hertwich, E.G., 2014. Climate policy through changing consumption choices: Options and obstacles for reducing greenhouse gas emissions. Glob. Environ. Chang. 25, 5-15.

Girod, B., Van Vuuren, D.P., Hertwich, E.G., 2013. Global climate targets and future consumption level: An evaluation of the required GHG intensity. Environ. Res. Lett. 8, 014016.

Gjerris, M., Gamborg, C., Saxe, H., 2016. What to Buy? On the Complexity of Being a Critical Consumer. J. Agric. Environ. Ethics 29, 81-102.

Goldstein, B., Hauschild, M., Fernandez, J., Birkved, M., 2017. Contributions of local agriculture to urban sustainability in the Northeast United States. Environ. Sci. Technol. 51, 7340-7349. 
Bjørn, A., Kalbar, P., Elsborg Nygaard, S., Kabins, S., Jensen, C. L., Birkved, M., Schmidt, J., Hauschild, M. Z. (2018). Pursuing necessary reductions in embedded GHG emissions of developed nations: will efficiency improvements and changes in consumption get us there? Global Environmental Change 52, 314-324. DOI: 10.1016/j.gloenvcha.2018.08.001

Gough, I., 2017. Recomposing consumption: defining necessities for sustainable and equitable wellbeing. Philos. Trans. R. Soc. A 375, 20160379.

Gram-Hanssen, K., 2010. Residential heat comfort practices: Understanding users. Build. Res. Inf. 38, 175-186.

Grubler, A., Wilson, C., Bento, N., Boza-Kiss, B., Krey, V., McCollum, D.L., Rao, N.D., Riahi, K., Rogelj, J., Stercke, S., Cullen, J., Frank, S., Fricko, O., Guo, F., Gidden, M., Havlík, P., Huppmann, D., Kiesewetter, G., Rafaj, P., Schoepp, W., Valin, H., 2018. A low energy demand scenario for meeting the $1.5^{\circ} \mathrm{C}$ target and sustainable development goals without negative emission technologies. Nat. Energy 3, 515.

Herrmann, I.T., Hauschild, M.Z., 2009. Effects of Globalisation on Carbon Footprints of Products. Cirp Ann. 58, 13-16.

IEA, 2016. Energy Technology Perspectives 2016 - Towards Sustainable Urban Energy Systems. International Energy Agency, France.

IIASA. International Institute for Applied Systems Analysis, 2014. AR5 Scenario Database Version 1.0.2. Available: https://tntcat.iiasa.ac.at/AR5DB/dsd?Action=htmlpage\&page=about (accessed 4.20.18).

IPCC, 2013. Climate Change 2013: The Physical Science Basis. Contribution of Working Group I to the Fifth Assessment Report of the Intergovernmental Panel on Climate Change. Cambridge University Press, Cambridge, United Kingdom and New York, NY, USA.

ISO, 2006a. 14040:2006. Environmental management - Life cycle assessment - Principles and framework.

ISO, 2006b. ISO 14044:2006. Environmental management - Life cycle assessment - Requirements and guidelines.

Ivanova, D., Stadler, K., Steen-Olsen, K., Wood, R., Vita, G., Tukker, A., Hertwich, E.G., 2015. Environmental Impact Assessment of Household Consumption. J. Ind. Ecol. 20, 526-536.

Jensen, C.L., 2017. Understanding energy efficient lighting as an outcome of dynamics of social practices. J. Clean. Prod. 165, 1097-1106.

Kalbar, P., Birkved, M., Kabins, S., Nygaard, S.E., 2016. Personal-Metabolism (PM) coupled with Life Cycle Assessment (LCA) Model: Danish Case Study. Environ. Int. 91, 168-179.

Kokoni, S., Skea, J., 2014. Input-output and life-cycle emissions accounting: Applications in the real world. Clim. Policy 14, 372-396.

Laakso, S., 2017. Giving up cars - The impact of a mobility experiment on carbon emissions and everyday routines. J. Clean. Prod. 169, 135-142.

Laakso, S., Heiskanen, E., Matschoss, K., 2017. D3.2 ENERGISE Living Labs background report. EU Horizon 2020 project 727642. ENERGISE. European Network for Research, Good Practice and Innovation for Sustainable Energy.

Laakso, S., Lettenmeier, M., 2014. Household-level transition methodology towards sustainable material footprints. J. Clean. Prod. 132, 184-191.

Luzecka, P., 2016. "Take a gap year!" A social practice perspective on air travel and potential transitions towards sustainable tourism mobility. J. Sustain. Tour. 24, 446-462.

McAloone, T., Bey, N., 2009. Environmental improvement through product development - a guide. Technical University of Denmark. 
Bjørn, A., Kalbar, P., Elsborg Nygaard, S., Kabins, S., Jensen, C. L., Birkved, M., Schmidt, J., Hauschild, M. Z. (2018). Pursuing necessary reductions in embedded GHG emissions of developed nations: will efficiency improvements and changes in consumption get us there? Global Environmental Change 52, 314-324. DOI: 10.1016/j.gloenvcha.2018.08.001

Merciai, S., Schmidt, J., 2018. Methodology for the Construction of Global Multi-Regional Hybrid Supply and Use Tables for the EXIOBASE v3 Database. J. Ind. Ecol. 22, 516-531.

Millar, R.J., Fuglestvedt, J.S., Friedlingstein, P., Rogelj, J., Grubb, M.J., Matthews, H.D., Skeie, R.B., Forster, P.M., Frame, D.J., Allen, M.R., 2017. Emission budgets and pathways consistent with limiting warming to $1.5^{\circ} \mathrm{C}$. Nat. Geosci. 10, 741-747.

Minx, J.C., Lamb, W.F., Callaghan, M.W., Bornmann, L., Fuss, S., 2017. Fast growing research on negative emissions. Environ. Res. Lett. 12, 035007.

Minx, J.C., Lamb, W.F., Callaghan, M.W., Fuss, S., Hilaire, J., Lenzi, D., Nemet, G., Creutzig, F., Amann, T., Beringer, T., de Oliveira Garcia, W., Hartmann, J., Khanna, T., Luderer, G., Nemet, G.F., Rogelj, J., Rogers, S., Smith, P., del Mar Zamora, M., 2018. Negative emissions: Part 1 - Research landscape, ethics and synthesis. Environ. Res. Lett. 13, 063001.

PwC, 2015. Conscious uncoupling? Low Carbon Economy Index 2015. PricewaterhouseCoopers LLP.

Rees, W.E., 1996. Revisiting carrying capacity: Area-based indicators of sustainability. Popul. Environ. 17, 195-215.

Rockström, J., Steffen, W., Noone, K., Persson, A., Chapin, F.S., Lambin, E.F., Lenton, T.M., Scheffer, M., Folke, C., Schellnhuber, H.J., Nykvist, B., de Wit, C.A., Hughes, T., van der Leeuw, S., Rodhe, H., Sorlin, S., Snyder, P.K., Costanza, R., Svedin, U., Falkenmark, M., Karlberg, L., Corell, R.W., Fabry, V.J., Hansen, J., Walker, B., Liverman, D., Richardson, K., Crutzen, P., Foley, J.A., 2009. A safe operating space for humanity. Nature 461, 472-475.

Rogelj, J., Elzen, M. Den, Fransen, T., Fekete, H., Winkler, H., Schaeffer, R., Sha, F., Riahi, K., Meinshausen, M., 2016. Perspective: Paris Agreement climate proposals need boost to keep warming well below $2^{\circ} \mathrm{C}$. Nature 534, 631-639.

Rogelj, J., Luderer, G., Pietzcker, R.C., Kriegler, E., 2015. Energy systems transformation for limiting endof-century warming to below $1.5^{\circ} \mathrm{C}$. Nat. Clim. Chang. 5, 519-527.

Røpke, I., 2009. Theories of practice - New inspiration for ecological economic studies on consumption. Ecol. Econ. 68, 2490-2497.

Ryghaug, M., Toftaker, M., 2014. A Transformative Practice? Meaning, Competence, and Material Aspects of Driving Electric Cars in Norway. Nat. Cult. 9, 146-163.

Sayre, N.F., 2008. The genesis, history, and limits of carrying capacity. Ann. Assoc. Am. Geogr. 98, 120134.

Schmidt, J.H., Weidema, B.P., Suh, S., 2010. FORWAST: Documentation of the final model used for the scenario analyses. Deliverable 6-4 of the EU FP6-Project FORWAST.

Shove, E., 2003. Converging Conventions of Comfort, Cleanliness and Convenience. J. Consum. Policy 26, 395-418.

Sørensen, P.B., Elmeskov, J., Frederiksen, P., Jacobsen, J.B., Kristensen, N.B., Morthorst, P.E., Richardson, K., 2015. Omstilling med omtanke - Status og udfordringer for dansk klimapolitik. Klimarådet (The Danish Council on Climate Change).

Sorrell, S., 2015. Reducing energy demand: A review of issues, challenges and approaches. Renew. Sustain. Energy Rev. 47, 74-82.

Spurling, N., Jensen, C., 2017. Practice interventions and Mobile Utopias: Workshop methods to make different long term transport futures. J. Consum. Cult. Submitted. 
Bjørn, A., Kalbar, P., Elsborg Nygaard, S., Kabins, S., Jensen, C. L., Birkved, M., Schmidt, J., Hauschild, M. Z. (2018). Pursuing necessary reductions in embedded GHG emissions of developed nations: will efficiency improvements and changes in consumption get us there? Global Environmental Change 52, 314-324. DOI: 10.1016/j.gloenvcha.2018.08.001

Spurling, N., Kuijer, L., 2016. Everyday Futures. Institute for Social Futures, Lancaster University.

Spurling, N., McMeekin, A., Shove, E., Southerton, D., Welch, D., 2013. Interventions in practice: reframing policy approaches to consumer behaviour. Sustainable Practices Research Group.

Stadler, K., Wood, R., Bulavskaya, T., Södersten, C.J., Simas, M., Schmidt, S., Usubiaga, A., AcostaFernández, J., Kuenen, J., Bruckner, M., Giljum, S., Lutter, S., Merciai, S., Schmidt, J.H., Theurl, M.C., Plutzar, C., Kastner, T., Eisenmenger, N., Erb, K.H., de Koning, A., Tukker, A., 2018. EXIOBASE 3: Developing a Time Series of Detailed Environmentally Extended Multi-Regional Input-Output Tables. J. Ind. Ecol. 22, 502-515.

Starkey, R., 2008. Allocating emissions rights: Are equal shares, fair shares? Tyndall Centre for Climate Change Research.

Statistics Denmark. Prices and consumption, 2016. FU51: Household yearly consumption by type of consumption, group of households and price unit. Available: http://www.statbank.dk/FU51 (accessed 4.20.18).

Steffen, W., Richardson, K., Rockström, J., Cornell, S.E., Fetzer, I., Bennett, E.M., Biggs, R., Carpenter, S.R., de Vries, W., de Wit, C.A., Folke, C., Gerten, D., Heinke, J., Mace, G.M., Persson, L.M., Ramanathan, V., Reyers, B., Sorlin, S., 2015. Planetary boundaries: Guiding human development on a changing planet. Science 347.

UN, 2015. World Population Prospects: The 2015 Revision, DVD Edition. United Nations, Department of Economic and Social Affairs, Population Division.

UNCTAD, 2016. Review of Maritime Transport 2016. United Nations Conference on Trade and Development. pp 7. ISBN 978-92-1-112904-5.

UNEP, 2015. The Emissions Gap Report 2015. United Nations Environment Programme (UNEP), Nairobi.

UNFCCC, 2015. Adoption of the Paris Agreement. Proposal by the President. Draft decision -/CP.21. United Nations Framework Convention on Climate Change (UNFCCC).

van Vuuren, D.P., Kok, M., Lucas, P.L., Prins, A.G., Alkemade, R., van den Berg, M., Bouwman, L., van der Esch, S., Jeuken, M., Kram, T., Stehfest, E., 2015. Pathways to achieve a set of ambitious global sustainability objectives by 2050: Explorations using the IMAGE integrated assessment model. Technol. Forecast. Soc. Change 98, 303-323.

van Vuuren, D.P., Stehfest, E., den Elzen, M.G.J., Kram, T., van Vliet, J., Deetman, S., Isaac, M., Goldewijk, K.K., Hof, A., Beltran, A.M., Oostenrijk, R., van Ruijven, B., 2011. RCP2.6: Exploring the possibility to keep global mean temperature increase below 2 degrees C. Clim. Change 109, 95-116.

WBCSD, 2014. Cement Sustainability Initiative. Getting the Numbers Right Project. Emissions Report 2014. World business council for sustainable development.

Wiedmann, T., 2009. Carbon footprint and input-output analysis - an introduction. Econ. Syst. Res. 21, 175-186.

Wood, R., Stadler, K., Simas, M., Bulavskaya, T., Giljum, S., Lutter, S., Tukker, A., 2018. Growth in Environmental Footprints and Environmental Impacts Embodied in Trade: Resource Efficiency Indicators from EXIOBASE3. J. Ind. Ecol. 22, 553-564.

World Steel Association, 2017. Personal communication with Jay Choi. Safety, Technology \& Environment Programme. World Steel Association. January, 2017. 